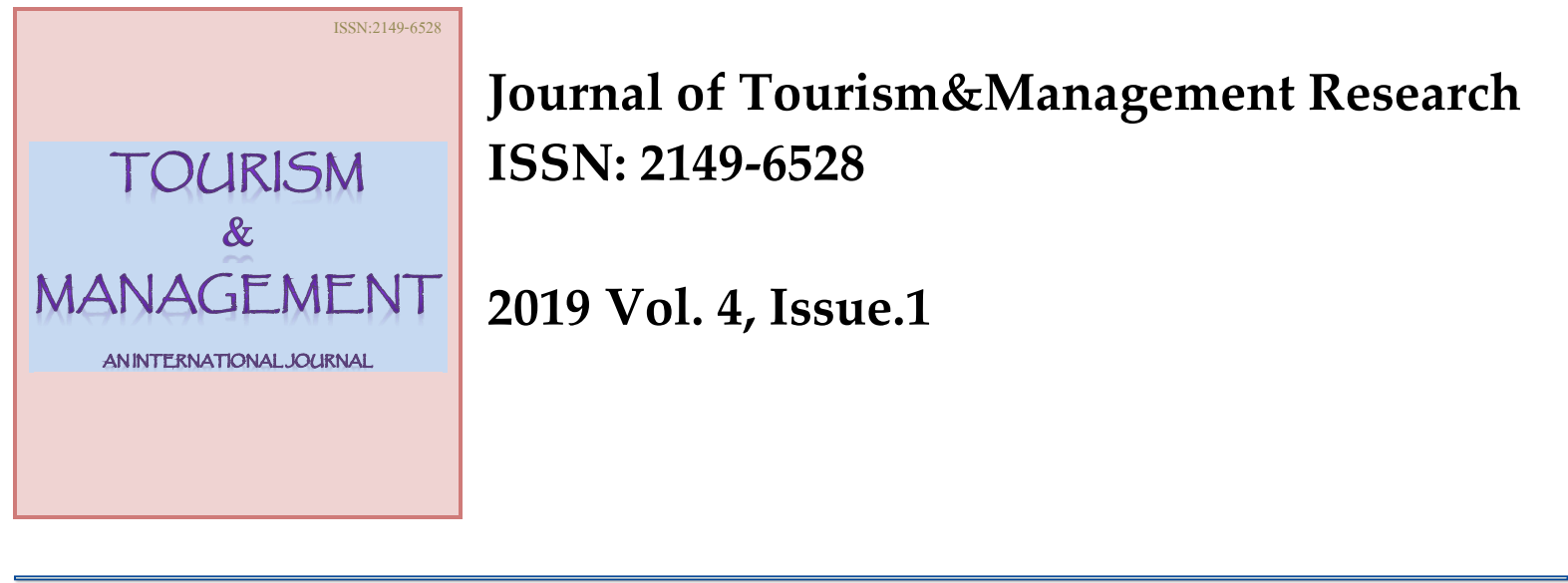

\title{
The Sociocultural Impacts of Language Tourism in Barcelona
}

\begin{abstract}
This paper aims to analyse the sociocultural impacts of inbound language tourism in Barcelona (Spain). This exploratory research followed a mixed-methods approach using different tools and techniques, including surveys to 176 language tourists and 37 host families. The majority of the language tourists surveyed were between 19 and 24 years old, stayed with host families or in shared apartments, and their main travel motivation was the destination itself. Those who opted for homestays sought to integrate better and learn more Spanish, but generally speaking integration was considered by most respondents the weakest aspect. Still, the reported gains were evident, not only in linguistic terms but also in relation to respondents' broad-mindedness. Host families also considered hosting international students a fruitful experience, which provided new perspectives and enabled them to rediscover their own culture. This study indicates that learning a foreign language overseas not only facilitates intercultural contact and the appreciation of cultural diversity, but can also change individuals' identity and values. Further research needs to investigate in practical terms ways to better integrate international students in the host community and which contexts facilitate interaction and personal growth to pave the way for enhanced sustainability in Barcelona's overcrowded tourism scene.
\end{abstract}

Keywords: Language tourism, Educational tourism, Sociocultural impacts, Transformational tourism, Overtourism

JEL Classification: I29, L83, Z13, Z32

Submitted: 08.12.2018; Accepted: 23.02.2019

Montserrat Iglesias, PhD. (Corresponding Author). School of Tourism, Hospitality and Gastronomy CETT-UB, University of Barcelona, Av. Can Marcet 36-38, 08035 Barcelona, Spain.

Email: montserrat.iglesias@cett.cat

Blanca Aliaga. School of Tourism, Hospitality and Gastronomy CETT-UB, University of Barcelona, Av. Can Marcet 36-38, 08035 Barcelona, Spain.

Email: blancaliamar@gmail.com

Veronica Corno. School of Tourism, Hospitality and Gastronomy CETT-UB, University of Barcelona, Av. Can Marcet 36-38, 08035 Barcelona, Spain.

Email: veero.k94@gmail.com 
Carla Luengo. School of Tourism, Hospitality and Gastronomy CETT-UB, University of Barcelona, Av. Can Marcet 36-38, 08035 Barcelona, Spain.

Email: carlaluengo.22@gmail.com

Joan Puigneró. School of Tourism, Hospitality and Gastronomy CETT-UB, University of Barcelona, Av. Can Marcet 36-38, 08035 Barcelona, Spain.

Email: joan11puignero@gmail.com

\section{Introduction}

Even though tourism is meant to foster brotherhood and peace (Reisinger, 2015; Singh, 2018), tourism eventually becomes what people make of it, and stakeholders and researchers should work towards the sustainability of destinations. The city of Barcelona, in Spain, should not be an exception. Despite the fact that tourism is Barcelona's major industry, the rise of tourism phobia has led citizens to demonstrate (Goodwin, 2016; Singh, 2018). These demonstrations have lately alternated with protests for and against self-determination, as Barcelona is located in the region of Catalonia, where a nationalist movement seeks independence from Spain. The official languages in Catalonia are Catalan and Spanish, and they coexist in daily communication.

In this worrisome context, responsible tourism options that can be the perfect ground for memorable experiences for the benefit of both tourists and residents need to be explored, particularly in overcrowded destinations like Barcelona (Goodwin, 2016). One such option may be educational travel, since it does not only facilitates learning and the acquisition of cultural and global knowledge, but also intellectual growth and personality development (Reisinger, 2015). This can be also applied to language tourism, a specific subtype of educational travel which may be defined as "a tourist activity undertaken by those travellers (or educational tourists) taking a trip which includes at least an overnight stay in a destination outside their usual place of residence for less than a year and for whom language learning is a primary or secondary part of their trip" (Iglesias, 2016, p.31).

Academic research on this specific tourism niche has been scarce. In Spain, little attention has been devoted to the development of language tourism in some World Heritage cities where Spanish language courses are offered to international students (Iglesias, 2018). Nevertheless, no scholarly investigations have been conducted so far considering Barcelona as a language tourism destination, hence the need to fill in this research gap.

In this study the sociocultural impacts of language tourism in Barcelona have been explored, both for the language tourists and the host community. The language tourists' profile and behaviour have been examined, the effect of accommodation on the relationship between language tourists and the host community has been analysed, and the influence of language tourists in the local community members they interact with has been investigated. Whereas previous publications following the same line of research have provided an overview of language tourism in Barcelona (see Aliaga et al., 2018), this study focuses more specifically on the language learners and the host community.

The relevance of researching the social impacts of tourism should not be overlooked, as it is vital to be aware of host communities and individual members' perceptions of the pros and cons of tourism. A balance needs to be attained to offset potential hostile reactions against tourists (Deery et al., 2012). Research on this topic started looking for definitions and concept development away from the predominant economic perspective from early tourism impact analysis, moved on to model development, continued with instrument design and development, and reached maturity with instrument testing and refinement. As a result, the key variables have been reported in terms of the relationship between host residents and tourists, the resident characteristics, the destination characteristics, the host resident perceptions of the social impacts of tourism on their communities, the quality of life and the 
social impact outcomes, which eventually lead to supportive or unsupportive attitudes towards tourism development (Deery et al., 2012).

The sociocultural effects of language tourism activities in the city of Barcelona have not drawn the scholars' attention, yet, and therefore need to be addressed. The outcomes deriving from a close look at this field of study will be reported subsequently, after presenting some related aspects underpinning it.

\section{Literature Review}

\subsection{Experiential Travel}

In their search of what constitutes a memorable experience for travellers, Tung and Ritchie (2011) draw from previous research on various definitional components, including the individuals' impressions, the personal outcomes in different stages of the trip, and the role of authenticity and serendipity (Tung and Ritchie, 2011). These authors define tourism experiences as "an individual's subjective evaluation and undergoing (i.e., affective, cognitive, and behavioural) of events related to his/her tourist activities which begins before (i.e., planning and preparation), during (i.e., at the destination), and after the trip (i.e., recollection)" (Tung and Ritchie, 2011, p. 1369).

Kim et al. (2012) state that a positive memorable tourism experience is "a tourism experience positively remembered and recalled after the event has occurred" (Kim et al., 2012 , p. 13). For these authors, the main factors that intervene in the memorability of tourism experiences are meaningfulness, involvement, local culture, knowledge, novelty, hedonism and refreshment (Kim et al., 2012). With the purpose of enhancing individuals' positive behavioural intentions and improving business prosperity, these components should be taken into account by destination managers for the development of tourism programmes. These variables can also be used to evaluate business performance and proper practices, or as a marketing tool for benchmarking and customer targeting (Kim et al., 2012).

Nevertheless, the experience economy, based on memorable experiences, should give way to the transformation economy (Pine and Gilmore (1999). This entails offering individual transformations built on life-transforming experiences going beyond the sheer provision of isolated memorable events. The own individuals should play an active role in fulfilling their aspirations and companies ought to stage a series of different events that allow individuals to experience self-actualisation. Therefore, besides creating the most propitious environment, it is fundamental to diagnose personal aspirations, to set realistic goals and guiding processes, to customise them to suit each person's profile, and to engage with them in a post-experience phase so that transformations are sustained through time (Pine and Gilmore, 1999). Of course, this approach can also be applied to travel and tourism.

Travel is usually considered to foster learning, cross-cultural awareness, sustainability and global mindedness (Lean, 2016). In fact, even though tourism is not transformative in itself, it can be conducive to personal transformation (Pritchard and Morgan, 2013). In the context of travel and tourism, personal transformation and learning are interrelated and determined by experience and critical reflection of what that experience entails (Reisinger, 2015). Only meaningful experiences give birth to transformational learning and trigger change (Reisinger, 2015), not only for travellers, but also for the destinations through which they travel, as well as for those destinations to which they return (Lean, 2016).

As they are away from their natural milieu, travellers can experience new lifestyles and come across new thinking systems that can lead them to modify their references. In turn, their transformed worldview and consciousness can derive into new, potentially far-reaching attitudes and lines of action (Reisinger, 2013). If they become aware of their new mind-set, their personal identity can be redefined and transformational learning and experiences can take place (Reisinger, 2015). This process can actually start before leaving their home environment and continue after they return home. 
A key aspect to understand oneself better, become more self-confident and open-minded and appreciate other individuals' reality is socialization (Reisinger, 2015). By interacting and connecting with the host population when travelling to other destinations instead of sticking with groups of fellow nationals, both tourists and the local community can learn from each other, negotiate new meanings and change their identities as long as their relationships of power are balanced (Wearing and Wearing, 2001). The host community, however, may be discouraged from meeting tourists and participating in cultural exchanges due to lack of familiarity or perceived negative impacts of tourism, for example in cultural and environmental terms (Reisinger, 2015). Conversely, "by experiencing tourism and tourists, host communities can generate new thoughts and ideas, create new meanings, change their social, cultural, political and environmental beliefs and, most importantly, move towards new values of openness, tolerance, sharing, empathy, compassion, justice and peace, unity and oneness, and service to others" (Reisinger, 2015, p. 12).

Due to their transformational potential, some types of tourism like educational, religious, volunteer, wellness, farm or backpacking, among others, foster not only self (re)discovery but also the development of new skills, the acquisition of new knowledge, and the generation of new expectations and experiences (Pritchard and Morgan, 2013). Nonetheless, the issue of how individual experiences can lead to transformative action at a societal level needs to be explored, as the creation of fairer communities requires the involvement ethically-minded businesses, consumers, organizations and employees (Pritchard and Morgan, 2013).

\subsection{Overtourism}

Social exchange theory has been a popular theoretical framework underlying research on host communities' attitudes. As stated by Ap (1992), social exchange theory is "a general sociological theory concerned with understanding the exchange of resources between individuals and groups in an interaction situation" (Ap, 1992, p. 668). From a tourism perspective, both host community members and tourists take part in an exchange and expect to obtain something out of it. Social exchange theory entails that the residents' support will be influenced by the perceived expected gains and costs drawing from tourism (Andereck et al., 2005). Therefore, residents will support tourist exchanges if they believe that the positive effects will outnumber the negative ones (Gursoy and Rutherford, 2004; Nunkoo and Ramkissoon, 2010).

Deery et al. (2012) have identified different categories of the social impacts caused by tourism on local communities found by researchers, namely economic benefits, opportunity cost, facility maintenance, new infrastructure, interesting activities, environmental issues, delinquent behaviour, increased prices, access denial, disruption, justice-related aspects, community pride, regional character, and showcase effect (in relation to a destination's projected image). Most of them can be actually aggravated by the phenomenon of overtourism.

Many countries nowadays try to balance the needs of the tourism industry, local residents, and tourists. According to a report produced by the World Travel \& Tourism Council (WTTC, 2017), overtourism can be exacerbated precisely by the main growth boosters of global tourism, i.e. the affluence of travellers, demographic shifts, the convenience of travel tools and resources, and the popularity of top attractions.

Following Peeters et al. (2018, p.15), "overtourism describes the situation in which the impact of tourism, at certain times and in certain locations, exceeds physical, ecological, social, economic, psychological, and/or political capacity thresholds". The main indicators include: bed-nights per $\mathrm{km}^{2}$ and per resident, the share of Airbnb bed capacity, air travel intensity, proximity to airports, ports and UNESCO World Heritage Sites, and the share of tourism in regional Gross Domestic Product (Peeters et al., 2018). 
In overcrowded destinations the tourist experience is threatened, while congestion, degraded landscapes and vandalism also generate discomfort among the residents, deriving into hatred between the host community and the visitors (Singh, 2018). The negative consequences for the quality of tourists' experiences concur with the damage to nature, to overloaded infrastructures, and to the local culture and heritage. They are coupled with social exclusion and with the economic harm caused by the disarticulation of local businesses, to the detriment of local economies (Peeters et al., 2018; WTTC, 2017). Thus, such destinations' authenticity can be minimised and their attractiveness can be compromised (Goodwin, 2017; Peeters et al., 2018). Due to the side effects of overcrowding on the local residents, they have openly expressed their concern for tourists' behaviour, noise, rising rents and the transformation of their neighbourhood's idiosyncrasy in cities like Barcelona, which is currently in the spotlight because of its high-profile struggle with overtourism (WTTC, 2017).

What can be done to prevent overtourism? It has been argued that responsible tourism might be a possible antidote, since it downplays the negative economic, social and environmental impacts on the host societies to the benefit of their welfare (Singh, 2018). In fact, responsible tourism entails using tourism to make better places to visit and live in so that it contributes to their sustainability (Goodwin, 2017). As it is easier to prevent overtourism than to recover from it, the key to sustainable development lies in proper planning and management practices. The study conducted by WTTC (2017) suggests that a comprehensive data base must be built on the different traveller segments that visit the destination and keep it updated to design informed tourism strategies. High high-value use cases and models should be articulated, too.

Furthermore, rigorous long-term planning must aim at respectful tourism, with a special emphasis on quality rather than quantity. Authorities and tourism stakeholders should constructively work hand in hand and involve all sections of society -social, commercial and public- to raise tourists' awareness to change their attitudes, evaluate the population's perspectives and ensure that their interests are taken into consideration (Andereck et al., 2005; Peeters et al., 2018).

As lines of action depend on the unique mix of challenges that every single destination needs to face, each one ought to develop, execute and supervise its own measures (Peeters et al., 2018). Some practical actions which can be implemented in the short and long term have been proposed in WTTC's report (2017).

To start with, in order to counteract imbalanced influxes of visitors, these should be distributed over time, so the promotional focus should be changed and the demand should be extended to shoulder or low seasons. Tourists should also be spread geographically to attract them to residential areas instead of jamming in bottlenecks. Less visited sites could be promoted, and new routes and highlights could be developed as well. The target, though, might rather be repeat visitors, since first-time visitors may not be willing to miss must-see attractions. On the other hand, in some cases tourist access and activities may have to be limited. Secondly, pricing should be adjusted to balance demand with supply, for instance by establishing fees and taxes or price segmentation based on visitor profiles, sustainability costs or time periods. Thirdly, the supply of accommodation should be regulated. The fact that housing stock can be easily turned into short-term rental supply has contributed to the boom of home-sharing, which can attract more visitors while raising long-term rental prices, to the detriment of local residents. The most convenient regulation for each destination depends on its tourism source and the balance of its short and long term rental market. With respect to home-sharing, market regulations may restrict the annual number of nights for short-term rents, limit the categories of housing stock available for renting, act against unlicensed rentals or even ban home-sharing. In Spain, regulations on short-term rentals have been passed in Barcelona, Ibiza, Majorca, and the Balearic Islands. The effects of the accommodation supply 
on the destinations can only be evaluated by examining the lodging offer in detail, including hotels and both licensed and unlicensed rentals.

\subsection{Accommodation in Barcelona}

A wide range of intermediation agencies, language schools and universities offer all kinds of services to foreign language students that wish to learn Spanish in Barcelona. Language tourists are mainly offered three kinds of accommodation, namely student's residences, homestays and shared apartments, which may be included or not in a package and may be facilitated or not by an intermediation agency (Iglesias, 2017).

Students' residences are usually well located and meals are often included. Social life in residences is usually lively, but as most of the other residents are usually international students too, this can turn into a disadvantage in terms of acquiring the target language. Actually, the relationships with other international students can help the students to integrate into their new life more easily and feel supported by their new friends, but it might also create an international bubble. Residence rooms can be shared or individual, and usually the price is higher than a shared apartment, but lower than a homestay. The student's residence offer in Barcelona is quite broad. Although the location or the package options are competitive items, each one has their own style and components that distinguish them from the rest. Two of the most popular residences in Barcelona are Melon District and Resa. The legal situation of the student's residences in Barcelona has been recently modified after the city hall decided to act against illegal tourist apartments, and they made a move on student's residences as well (Goodwin, 2016). In 2016 the city hall of Barcelona penalised a number of residences because they used their facilities to host tourists coming to this city for vacation instead of for study purposes, mostly in summer, when the all-year-round students went home.

On the other hand, homestay offers opportunities for deep immersion in the local culture and language. Staying with a host family is the most recommended option by language tourism providers, since as well as enhancing the interaction between host families and tourists it also fosters cultural awareness and respect between tourists and the local community. Nevertheless, homestays can also have negative effects if the relationship between the students and the host family is tense and the communication is null (Aliaga et al., 2018).

Last but not least, apartments are highly recommended as long as foreign students share them with local people they can practice the target language with. In addition, the local residents can help the student to integrate in the destination, take part in local activities with them, discover the area and meet new friends. International students can find the best accommodation option to suit their needs by means of worldwide known web sites specialising in student lodging, such as Homestay, Uniplaces, HousingAnywhere or ErasmusInn. Yet, the number of illegal establishments and tourist dwellings that operate in the city of Barcelona is scandalous. The impact of home-sharing on Barcelona has been noteworthy, and in 2016 more than 1.2 million visitors stayed in Airbnb rentals (WTTC, 2017). Every lodging arrangement can have different impacts on the whole study abroad experience. The study reported hereinafter aimed at exploring the relationship between accommodation and integration in the local culture, as well as the outcomes of contact between local residents and language tourists in Barcelona in sociocultural terms.

\section{Methodology}

This exploratory research followed a mixed methods approach, and data collection took place between March and May 2017. In order to obtain first-hand information from the language tourism providers, language tourists, host families and other local residents both quantitative and qualitative techniques were employed. 
On the one hand, two in-depth interviews were carried out: first to language tourism providers and then to local residents other than host families. For this qualitative technique, a specific semi-structured script was generated for both sources of information. On the other hand, quantitative information from international students and host families was obtained through surveys. A structured questionnaire for the students and another one for the host families were created, both of them with different types of questions: closed, open and mixed. These self-completed questionnaires also included dichotomous questions, multiple-choice questions, open-ended questions, ratio scale questions and five-point Likert scale questions.

The secondary source research required literature review and internet exploration in order to extract the relevant information through content analysis, which allowed to pinpoint the providers of language tourism for international students wishing to study Spanish in Barcelona. A fact sheet for each one of them was elaborated, and ultimately a number of providers were selected and contacted for an interview. As for the interview to local residents, the research team contacted some friends of international students who had used the services of two of the providers. A detailed account of the secondary data content analysis and the indepth interviews can be found in Aliaga et al. (2018).

A snowball sampling method was used for the surveys. Thus, at the end of the interviews with the providers they were asked to distribute the online student questionnaire to their students and circulate the online host family questionnaire among the host families they were currently working with. In addition, printed questionnaires were handed out to the international students by the research team, who transferred the information to an online Google Form.

The universe of this study was hardly quantifiable and encompassed four different population segments: first, all the language schools and the language tourism providers in Barcelona which offer at least 4 hours of Spanish courses per week; second, all the international students of Spanish staying in Barcelona during their language tourism experience; third, all the host families in Barcelona that host international students of Spanish in their home during their language trip; and finally, all the local community members that interact with international students of Spanish during their stay in Barcelona. The sample was eventually composed of 12 language tourism providers, 176 language tourists, 37 host families and 5 local community members. Table 1 shows the information collected from each one of the language tourism providers through in-depth interviews to providers, in-depth interviews to locals, surveys to students and surveys to host families.

Table 1: Fieldwork sources.

\begin{tabular}{|c|c|c|c|c|}
\hline Provider & IP & SS & SHF & $\mathrm{IL}$ \\
\hline Academic Programs International (API) & $\mathrm{X}$ & & & \\
\hline Arcadia University & $\mathrm{X}$ & & $X$ & \\
\hline Barcelona Academic Services (BAS) & $\mathrm{X}$ & & & $\mathrm{X}$ \\
\hline BCNLIP & $\mathrm{X}$ & $\mathrm{X}$ & & \\
\hline CEA Study Abroad & $\mathrm{X}$ & & $\mathrm{X}$ & \\
\hline Education Fist (EF) & $\mathrm{X}$ & $\mathrm{X}$ & & \\
\hline Enforex & & $\mathrm{X}$ & & \\
\hline International Studies Abroad (ISA) & $\mathrm{X}$ & $\mathrm{X}$ & $\mathrm{X}$ & $\mathrm{X}$ \\
\hline Linguaschools & $\mathrm{X}$ & $\mathrm{X}$ & & \\
\hline Ole Languages & $\mathrm{X}$ & $X$ & & \\
\hline Speakeasy & $\mathrm{X}$ & & & \\
\hline
\end{tabular}


Note: Crosses (X) indicate the data collection techniques used, namely in-depth interviews to providers (IP), indepth interviews to locals (IL), surveys to students (SS) and surveys to host families (SHF).

The data gathered from the questionnaires were analysed through two coding systems and data matrices, one for the students' questionnaires and one for the host families' questionnaire. On the other hand, the in-depth interviews were recorded, transcribed, and processed through categorisation. Distinct categories were created, and the answers were broken down into first level concepts and transferred into two spreadsheets, one with the providers' replies and the other one with the providers' replies.

In view of the findings deriving from each data corpus, the final conclusions were built by connecting data through the triangulation of perspectives and methods in order to have an unprecedented overview of language tourism in Barcelona from different angles.

\section{Results}

As the results obtained through the content analysis of secondary sources and in-depth interviews have already been reported by Aliaga et al. (2018), this study will specifically analyse and interpret the information collected through each one of the surveys. The most outstanding findings with regard to each questionnaire were divided in different categories as follows.

\subsection{International Students}

Profile and motivation - To start with, it must be pointed out that the respondents were spring or all-year-round students of Spanish. Women (68.2\%) outnumbered men, and most of them were from Europe (48\%) -probably due to the geographic proximity-, followed by America (28\%), Asia (23\%) and Oceania (1\%). However, the individual countries that sent more international students to Barcelona were the USA (17.8\%) and China (14.8\%), followed by Germany ( $8 \%$ ). This may be due to the fact that almost all the third party exchange providers interviewed specialise in the American market.

As for the length of their stay in Barcelona, 35.8\% of the students stayed between 7 and 12 months, $35.2 \%$ between 4 and 7 months, $21.6 \%$ between 1 and 3 months, $6.3 \%$ between 3 and 4 weeks, and only $1.1 \%$ between 1 and 2 weeks. These percentages could be related to the fact that the questionnaires were handed to the students during the spring semester and not in the summer, which is the season that usually hosts shorter programmes.

The age of the students was mostly between 19 and 24 (59.1\%), followed by more than $25(28.4 \%)$ and between 14 and $18(12.5 \%)$. The low percentage of between 14 and 18-yearold students can also be linked to the data collection period. Young students usually start their experiences abroad with shorter programmes in summer, when they are on holidays.

The most important factor when choosing a provider was the destination itself $(43.5 \%)$. To be more specific, the main reasons that pushed students to come to Barcelona were the weather $(71.6 \%)$, the culture $(68.2 \%)$ and the location $(52.8 \%)$, while other factors like food, recommendations, nightlife or safety were secondary for the students.

Satisfaction and benefits of the language tourism experience - The results shown in Figure 1 indicate that the students were quite satisfied with different aspects of their stay, since almost all of them were rated as quite satisfactory, except for one of them which stands out from the rest: the destination itself. Barcelona was the factor with the highest rating, as $62.5 \%$ felt very satisfied with the city and felt it accomplished their expectations, and $30.1 \%$ rated it 4 out of 5 . It must be highlighted that no one ranked Barcelona as very unpleasant.

Conversely, the factor with lower rates was integration. Only $18.2 \%$ felt very integrated into the local culture, and they mostly felt quite integrated (36.9\%) and more or less 
integrated (33.5\%). As for the overall experience, $38.6 \%$ felt very satisfied, $44,3 \%$ quite satisfied, $14.2 \%$ remained neutral, and just a minority provided low ratings.

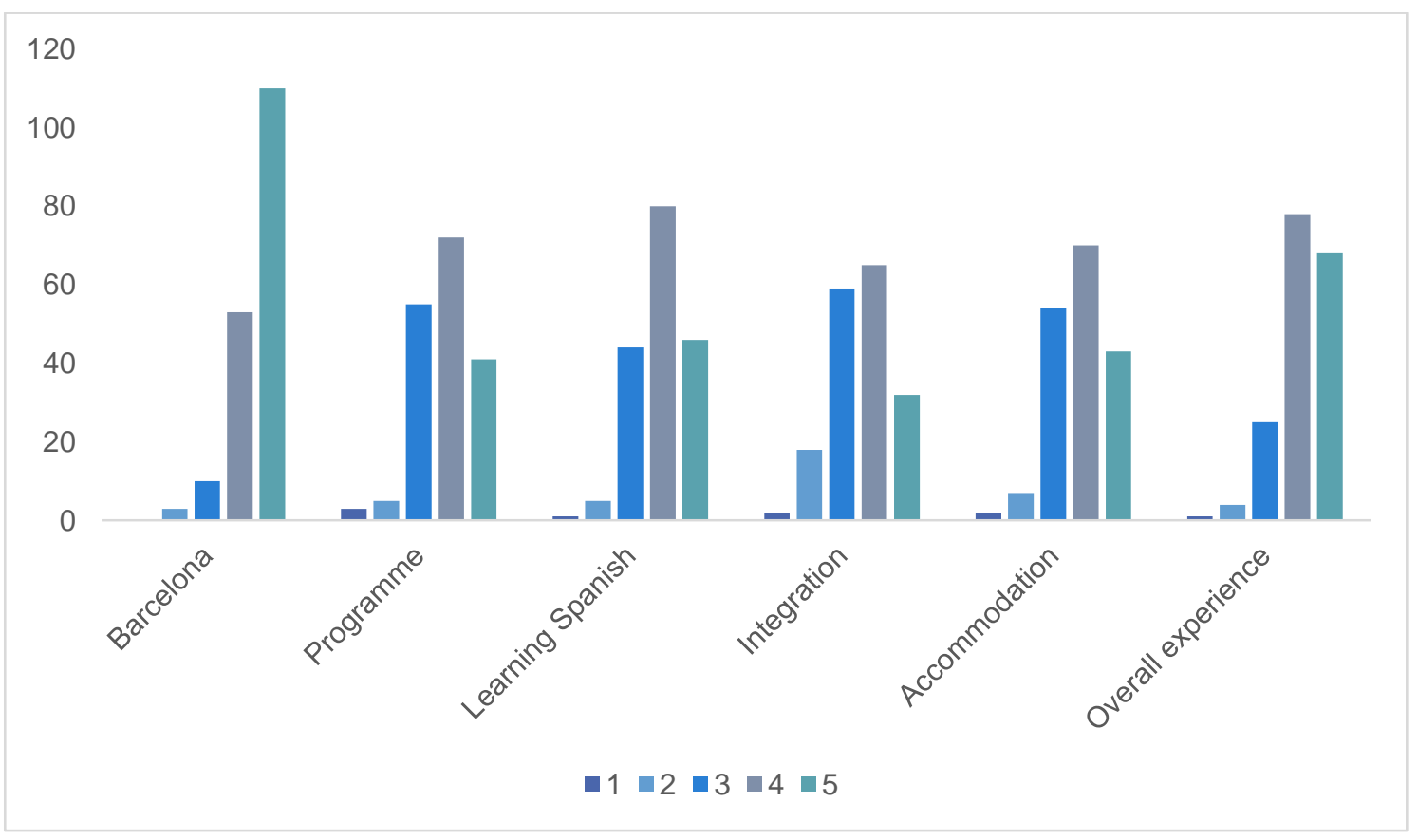

Figure 1: Satisfaction of the students with the experience (rated from 1 to 5).

All in all, $34.80 \%$ of the respondents felt they had improved their language skills thanks to their sojourn, $24.70 \%$ considered themselves more open-minded and tolerant after their experience abroad, $23.20 \%$ thought they had become more independent and responsible, and $17.30 \%$ acknowledged the fact that they appreciated more their background after living in another country.

Linguistic aspects and behaviour - The vast majority of the students came to Barcelona with no previous knowledge of Spanish (33\%), or really basic Spanish skills (47.2\%), whereas $14.8 \%$ had an intermediate level, and only $5 \%$ had an advanced level upon their arrival in Barcelona. The results also show that the majority of the students $(67.1 \%)$ thought Catalan was not a barrier for learning Spanish.

There is a noticeable relationship between the students' prior level of Spanish and the improvement of their language skills during their stay. The students that initially had a low level of Spanish saw their improvement as very considerable: $50.4 \%$ believed that they had improved quite a great deal and $21.3 \%$ a great deal. On the contrary, among the students that already had a high level of Spanish, only $8 \%$ affirmed that they had improved very considerably, and $45.7 \%$ considered that they had improved quite considerably. Obviously, the ceiling effect can be a factor that prevents more advanced language learners from appreciating their progress, while lower level students can be more aware of and satisfied with their evolution.

It is important to highlight that $57.4 \%$ of the respondents admitted that they barely spoke in Spanish, 27.8\% spoke quite often, 13.6\% always spoke in Spanish and 1.2\% never spoke in Spanish and communicated in other languages. Among those students that barely spoke in Spanish, 46\% spoke with locals, 37\% with shop attendants, and 17\% with their host family.

As regards the activities that they carried out, they were principally undertaken with other international students, and not many students mingled with local residents. The activities in which locals were more involved were those related to gastronomy and nightlife (see Figure 2). 


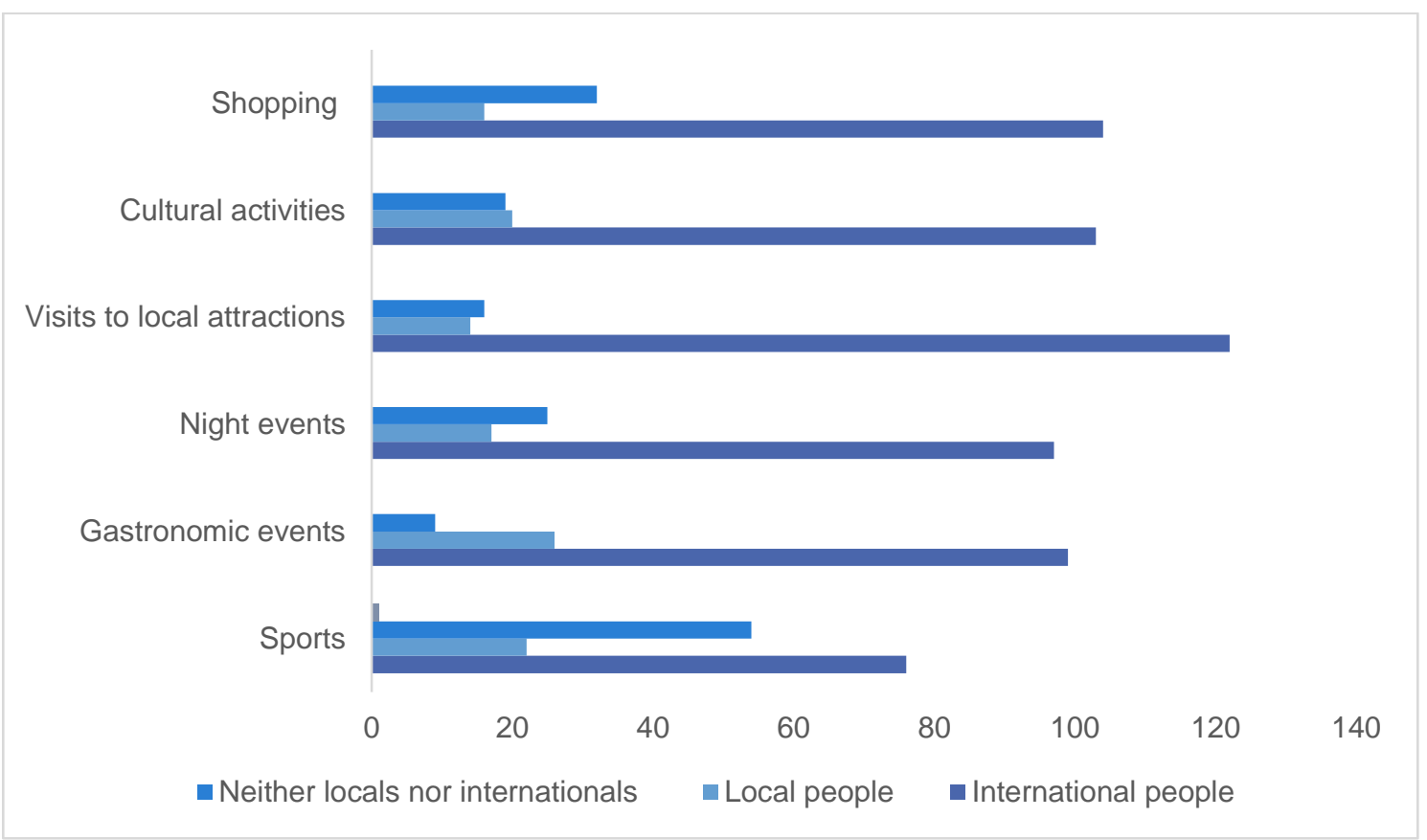

Figure 2: Activities carried out with local residents and with other international students.

Accommodation - Most of the international students opted for a shared apartment (44\%), a homestay $(32 \%)$, a students' residence $(18 \%)$, and to a minor extent, for their own apartment (5\%) or Airbnb (1\%).

Through a more in-depth analysis a correlation between the type of accommodation and the age of the tourists can be observed. Among the students aged between 14 and 18, half of them preferred homestays, 32\% lodging at a student's residence and $18 \%$ sharing an apartment. The most popular options for students between 19 and 24 were a shared apartment $(42 \%)$, homestays $(32 \%)$ and a student's residence $(22 \%)$. Finally, older students mainly chose a shared apartment (60\%), homestays $(24 \%)$ or their own apartment $(10 \%)$.

On the other hand, when relating the type of accommodation to the length of the students' stay it can be observed that for sojourns of below three months the three top types of accommodation were very similar, but for longer stays students' residences were less popular. This could be due to the high price of the residences, particularly in peak periods. Lastly, the students that stayed for less than a month usually chose a homestay or a shared apartment.

Concerning the reasons that pushed the students to choose each type of accommodation, those that chose homestays mostly did it to integrate better in the culture (39\%) and to learn more Spanish (39\%). The ones staying in a students' residence were pushed by the motivation of being more independent (47\%) and meeting more international students (34\%), while those choosing a shared apartment wanted to be independent (40\%) and learn more Spanish (22\%), probably because they expected to have Spanish roommates.

\subsection{Host Families}

Profile and motivation - Practically all the respondents (93.7\%) affirmed they would host students again in the future. They had hosted students more than three times $(67.7 \%)$, three times $(13.5 \%)$, once $(10.8 \%)$ and twice $(8 \%)$. The fact that the providers sent the questionnaire to the families with whom they had a stronger relationship can be one of the reasons for this high hosting frequency.

The families that had been hosts more than three times were driven by the primary motivation of connecting with international students $(30 \%)$, followed by the economic 
incentive (23\%), the desire to show their culture (19\%), the need of company (14\%), because their kids had in turn been hosted by another family abroad (7\%), or because their kids wanted to host international students $(7 \%)$.

Linguistic aspects - The vast majority of the host families (97.3\%) spoke in Spanish with the students, although Catalan (10.8\%) and English (10.8\%) were also used, as some families mixed languages. It might seem surprising that some host families spoke to the students in Catalan, but in some specific programmes families may not be required to talk to the students just in Spanish, since this is regarded as a cultural asset. In fact, $70.3 \%$ of the families did not think Catalan was a barrier to learn Spanish.

Most of the families rated the time spent in conversations with the students as average and above average, i.e. quite frequently. By the end of the students' stay, $59.5 \%$ of the families thought that the students' language skills had improved above average and $29.7 \%$ believed that they had improved remarkably.

With respect to the correlation between linguistic improvement and length of stay, $80 \%$ of the students who stayed between 1 and 3 months perceived that they had improved above average, whereas $42 \%$ of those staying between 4 and 6 months also noticed an improvement of above average. Most remarkably, in stays of between 7 and 12 months, 50\% noticed an improvement of above average and $40 \%$ considered that their improvement had been outstanding.

Integration - As for the adaptation of the students to family life, the host families evaluated different aspects, as shown in Figure 3. The lowest aspect ranked was the interaction between the student and the family, while the highest rated was the student's adaptation to meals. Respecting the integration in the families, the ratings were quite polarised, i.e. either high or low, while the adaptation to the house rules was more homogeneous.

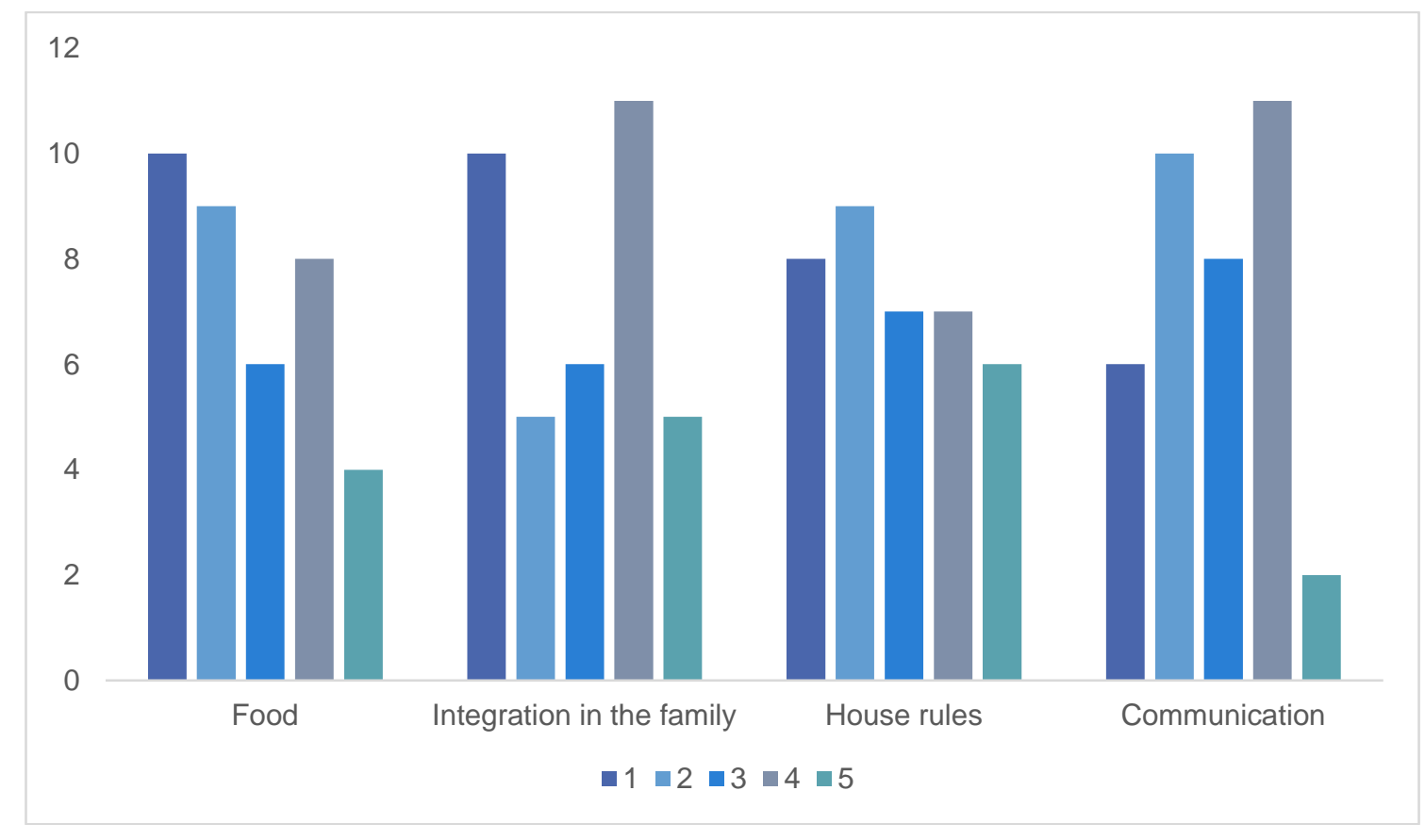

Figure 3: Integration of the student in the host family life (rated from 1 to 5).

On the whole, $45.9 \%$ of the families did not report any problem with the students during their stay, and when they had any problems they were due to the student's bad behaviour $(32.4 \%)$, they experienced problems with the student's adaptation $(16.2 \%)$ or had minor 
problems of different nature $(6 \%)$. Nevertheless, in $83.8 \%$ of the cases a solution was found and the students remained in the house.

Satisfaction and benefits of hosting international students - In relation to the families' perceived satisfaction with their hosting experience, the most repeated value was 5 out of 5 on a five-point Likert scale: $70.3 \%$ evaluated their experience as extremely positive, $24.3 \%$ as positive, and 5.4\% rated it with a value of 3 out of 5 . Nobody showed dissatisfaction or rated it below average. In fact, the average satisfaction value was 4.65 with a standard deviation (SD) of 0.59 .

Most of the families rated their relationship with the students high and very high, with an average value of 4.27 out of 5 and a SD of 0.84 , and their major reason for hosting an international student was the experience itself, which they considered enriching. It can be confirmed, therefore, that the economic benefit was often regarded as a secondary motivation. Concerning family activities, $62.2 \%$ of the families affirmed that they did more activities than usual when they were hosting an international student. Actually, $94.6 \%$ of the families carried out outdoor activities once a week, and they were mainly cultural (75.5\%), gastronomic $(67.6 \%)$ and related to sports $(32.4 \%)$. The vast majority (94.6\%) stated that they learnt more about their own culture by showing it to the international students that they hosted and doing activities together.

\section{Conclusion, Implications and Limitations}

The results of this study reveal that there was a statistically significant relationship between the accommodation used by the international language students investigated in Barcelona, their motivations and their linguistic progress, especially at certain ages and in relation to other factors such as prior language level and sojourn length. Other perceived benefits of the language tourism experience have been drawn forth, for instance in terms of personal development, respect for otherness and identity awareness. Moreover, their integration in the local culture and community has been put in the spotlight.

The survey results also prove that hosting an international student was a very satisfactory experience for the host families under study. These outcomes are consistent with the ones reported in Aliaga et al. (2018), according to which the bonds between the international students and their local friends were strong, and they kept in touch after returning to their home country. It can also be concluded that in the locals' view, thanks to the language students and the activities they did with them, their local acquaintances and host families somehow rediscovered their own culture.

All in all, though, some remarks and practical implications must be taken into consideration. Most of the respondents claimed that they did not feel integrated in the local culture, as their interaction with locals was limited, so they would require more contact opportunities. Most of the activities involving locals are similar in the different study abroad programmes on offer. Since they do not seem to work well enough from the international students' point of view, common areas of interest should be identified among both visitors and residents.

On the other hand, the providers should consider holding events with the local families and international students, which can help them in three respects: expanding their connections, integrating better and creating an emotional bond between the host families and the programme itself. They could also organise gatherings for the host families where they can share their experiences.

All the main aspects of memorable tourism experiences identified by Ritchie and McCormick (2012) can be found in language tourism, in which social interaction, learning and cultural immersion are the basic ingredients. Homestays can be the perfect ground for novelty and involvement, as international students can engage emotionally in meaningful social interactions with their host families and their new friends while having fun with them 
and getting to know the local culture from the inside. Sharing apartments or staying in student residences with other international students can also offer opportunities for strong emotional involvement and new knowledge. Furthermore, the leisure activities sojourners undertake can be a source of hedonism and refreshment. Both leisure activities and language learning tasks can actually allow them to acquire knowledge and discover more about their own skills and/or the local culture (Iglesias, 2017).

The transformational potential of educational travel has already been underscored. Such potential can be magnified when complemented by other transformational types of tourism also pinpointed by Pritchard and Morgan (2013). Language tourism, in particular, can be successfully combined with cultural and heritage travel, volunteering, farm stays or naturebased sojourns, just to mention a few. This not only enhances learning and self (re)discovery, but is also a further step towards self-actualisation, leading to moral and ethical development, as well as promoting altruism, connectedness with others, responsible attitudes and concern for society (Reisinger, 2015).

Our results indicate that although further meaningful contact between language tourists and host community members is needed, the respondents' behaviour was generally respectful, and some even acknowledged their discoveries and the changes they had undergone. It must be borne in mind, though, that the transformational effect of individual experiences on society requires the involvement of all stakeholders (Pritchard and Morgan, 2013).

One of the possible benefits of language tourism for society may be noticeable in overcrowded destinations. The report elaborated by WTTC (2017) highlights that a comprehensive data base of visitors should be built for enhanced strategic planning, and highvalue cases and models should be taken into account. A language tourism observatory would serve that purpose, both at a domestic and at an international level (Iglesias, 2018). Moreover, the report states that rigorous long-term planning must be carried out aiming at responsible tourism, and offers examples of former sun and beach destinations that managed to somehow shift to community-based destinations where visitors can interact with the country's culture and heritage. A number of Spanish cities have started diversifying their tourism offer to emphasise their cultural value, some of them in relation to language tourism, like Salamanca or Córdoba (Iglesias, 2018). These and other similar cases could be valuable referents. Of course, as every destination has a unique challenging situation, successful lines of action must be taylor-made, and decisions on which is the main concern need to be taken: Is the priority preserving residents' quality of life? Improving the tourist experience? Protecting sites? (WTTC, 2017). Language tourism may be a way of finding a certain balance.

Such balance may entail distributing influxes visitors over time (WTTC, 2017). Our results show that the vast majority of language tourists stayed in Barcelona for more than three months. This finding correlates with other research outcomes according to which language tourism is less seasonal than other types of tourism by far (Iglesias, 2018).

In addition, visitors should also be spread geographically, so less visited tourist attractions could be promoted and new routes could be developed, particularly targeted at repeat visitors (WTTC, 2017). Since language tourists tend to have longer sojourns they do not need to visit must-see attractions in the peak season, and they also discover less known spots as advised by providers and local acquaintances, sometimes accompanied by them. As a matter of fact, the language travellers who establish emotional bonds with a certain destination are likely to return and even bring along first-time visitors (Iglesias, 2017). Therefore, language tourism providers try to put new routes, highlights, learning and leisure proposals at their customers' disposal to offer them diverse, authentic alternatives.

As for balancing demand with supply through price segmentation on the basis of tourist profiles or time periods, international language students also have a role to play, especially long-term visitors with cultural interests. Establishing different fees for residents or students is nowadays a standard practice in many destinations, including Barcelona (WTTC, 2017). 
Similarly, language travel can be a tourism source to be taken into account in terms of regulating the accommodation supply in overcrowded destinations like Barcelona, which have already taken the first steps in this direction, as already mentioned.

In spite of the fact that Barcelona is reportedly a paradigmatic overcrowded destination, neither the international students nor the host families that took part in our research complained about it, probably because they looked at this city with different eyes, through the lens of positivism and respect. Even though the countries with a high ratio of tourists per inhabitants are the most affected, mainly in Europe, overtourism must be considered a global problem (Singh, 2018). Sustainably managed language tourism experiences may be a way to counteract it, and the transformational impact on those who take part in them could be one of the keys which should not be overlooked in future tourism planning, development and implementation.

Despite its obvious limitations, our research suggests that it is worth considering if language tourism might be a responsible alternative to mass tourism in Barcelona to a lesser extent, even though its scope and impacts are comparatively far more reduced. Admittedly, the representativeness of this empiric study is limited owing to its restricted sample size. Since snowball sampling was the method used to find the respondents, having access to more providers would have entailed the participation of a larger amount of international students, host families and locals. However, initiating contact by email with the different language providers was not easy.

Besides, time constraints also intervened in this cross-selectional data study. Further research could compare different segments and/or could be undertaken in different time periods, as a longitudinal study could offer greater insight with respect to language students' profiles and the current situation of language tourism in Barcelona.

In the light of the increasingly close relationship between social and academic programmes abroad, other potential research avenues could be oriented towards the motivation to acquire a second language abroad in volunteering sojourns. Actually, as integration and language progress are interconnected, future studies could not only explore in practical terms ways to better integrate international students in the host community, but also how their communicative competence in the target language develops, and which contexts facilitate integration and linguistic development.

Additionally, since the accommodation arrangements made by international students have not been investigated in depth, the role of student's residences and other emerging options within the sector, such as Airbnb, might be looked at too. Likewise, given that the economic impact of language students for the city of Barcelona has not been analysed either, a detailed large-scale study examining their spending habits would shed light on the sustainability of this type of tourism, mostly as an alternative to mass tourism.

\section{References}

Aliaga, B., Corno, V., Iglesias, M., Luengo, C. and Puigneró, J. (2018). Trips of the Tongue: Language Tourism in Barcelona, Ara Journal of Tourism Research, 8(1), 7-20. http://revistes.ub.edu/index.php/ara/article/view/20092. [Accessed 6 August 2018].

Andereck, K.L., Valentine, K.M., Knopf, R.C. and Vogt, C.A. (2005). Residents' perceptions of community tourism impacts, Annals of Tourism Research, 32(4), 1056-1076.

Ap, J. (1992). Residents' perceptions on tourism impacts, Annals of Tourism Research, 19(4), 665-690.

Deery, M., Jago, L. and Fredline, L. (2012). Rethinking social impacts of tourism research: A new research agenda, Tourism Management, 33(1), 64-73.

Goodwin, H. (2016). Managing Tourism in Barcelona, Progress in Responsible Tourism, 5(1), 28-48. https://www.goodfellowpublishers.com/ [Accessed 28 January 2019]. 
Goodwin, H. (2017). The challenge of overtourism. Responsible Tourism Partnership Working Paper 4. http://haroldgoodwin.info/pubs/RTP'WP4Overtourism01'2017.pdf. [Accessed 28 January 2019].

Gursoy, D. and Rutherford, D.G. (2004). Host attitudes toward tourism: An Improved structural model, Annals of Tourism Research, 31(3), 495-516.

Iglesias, M. (2016). The Language Tourism Market System: Conceptualising Language Tourism, International Journal of Scientific Management and Tourism, 2(1), 25-40. http://www.ijosmt.com/index.php/ijosmt/article/view/69/79. [Accessed 14 August 2018].

Iglesias, M. (2017). The role of travel-related aspects in the language tourism experience, Enlightening Tourism. A Pathmaking Journal, 7(2), 125-153. http://www.uhu.es/ [Accessed 28 November 2018].

Iglesias, M. (2018). Turismo idiomático en España. Marco teórico, International Journal of Scientific Management and Tourism, 4(1), 29-59. http://www.ijosmt.com/index [Accessed 30 November 2018].

Kim, J.H., Ritchie, J.B. and McCormick, B. (2012). Development of a scale to measure memorable tourism experiences, Journal of Travel Research, 51(1), 12-25.

Lean, G. (2016). Mobilizing travel and transformation. In G. Lean (Ed.), Transformative travel in a mobile world (pp. 1-16). Wallingford, UK: CABI.

Nunkoo, R. and Ramkissoon, H. (2010). Modeling community support for a proposed integrated resort project, Journal of Sustainable Tourism, 18(2), 257-277.

Peeters, P., Gössling, S., Klijs, J., Milano, C., Novelli, M., Dijkmans, C., Eijgelaar, E., Hartman, S., Heslinga, J., Isaac, R., Mitas, O., Moretti, S., Nawijn, J., Papp, B. and Postma, A. (2018). Research for TRAN Committee - Overtourism: impact and possible policy responses. Brussels: European Parliament, Policy Department for Structural and Cohesion Policies. https://www.cstt.nl/ [Accessed 28 January 2019].

Pine, B.J. and Gilmore, J.H. (1999). The experience economy: work is theatre \& every business a stage. Boston, MA: Harvard Business School Press.

Pritchard, A. and Morgan, N. (2013). Hopeful tourism: A transformational perspective. In Y. Reisinger (Ed.), Transformational tourism: Tourist perspectives (pp. 3-14). Wallingford, UK: CABI.

Reisinger, Y. (2013). Preface. In Y. Reisinger (Ed.), Transformational tourism: Tourist perspectives (pp. xii-xv). Wallingford, UK: CABI.

Reisinger, Y. (2015). Preface. In Y. Reisinger (Ed.), Transformational tourism: Host perspectives (pp. xii-xiii). Wallingford, UK: CABI.

Reisinger, Y. (2015). Personal Transformation and Travel and Tourism. In Y. Reisinger (Ed.), Transformational tourism: Host perspectives (pp. 6-14). Wallingford, UK: CABI.

Singh, T.V. (2018). Is over-tourism the downside of mass tourism?, Tourism Recreation Research, 43(4), 415-416. https://www.tandfonline.com/ [Accessed 20 November 2018].

Tung, V.W.S. and Ritchie, J.B. (2011). Exploring the essence of memorable tourism experiences, Annals of tourism research, 38(4), 1367-1386.

Wearing, S. and Wearing, B. (2001). Conceptualizing the selves of tourism, Leisure studies, 20(2), 143-159.

World Travel \& Tourism Council. (2017). Coping with success: Managing overcrowding in tourism destinations. https://www.wttc.org/priorities/sustainable-growth/destinationstewardship/. [Accessed 21 November 2018]. 


\section{Author Biography}

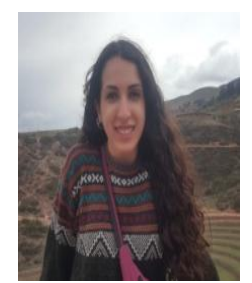

Blanca Aliaga completed her bachelor's degree in Tourism and Hospitality Management at the School of Tourism, Hospitality and Gastronomy CETT-UB, University of Barcelona, Spain. She is currently working as a front desk agent at a luxury hotel in Barcelona.

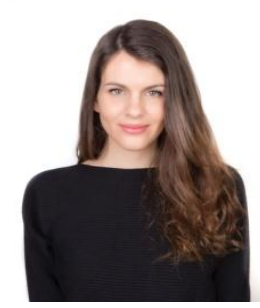

Veronica Corno completed her bachelor's degree in Tourism and Hospitality Management at the School of Tourism, Hospitality and Gastronomy CETT-UB, University of Barcelona, Spain. She then pursued a master's degree in International Relations at Blanquerna, Ramón Llull University, Spain. She has relevant international background through various study-abroad programmes and internships and has worked in different non-governmental organisations. Her research interests include environmental policy, climate change and tourism.

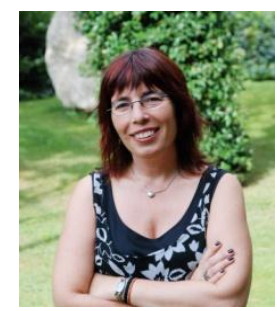

Montserrat Iglesias is a senior lecturer of English as a Foreign Language and the head of studies at CETT Language School from the School of Tourism, Hospitality and Gastronomy CETT-UB, University of Barcelona, Spain. She holds a PhD in Education from the University of Barcelona. Her research focuses on the development of oral communicative competence in English for Specific Purposes and on language tourism.

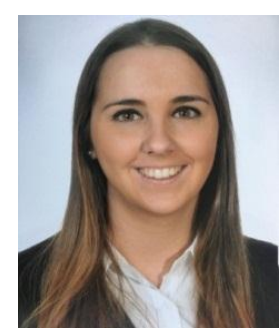

Carla Luengo completed her bachelor's degree in Tourism and Hospitality Management as well as a Revenue Management programme at the School of Tourism, Hospitality and Gastronomy CETT-UB, University of Barcelona, Spain. She is currently working as a guest relations agent at a 4-star superior hotel in Barcelona. 


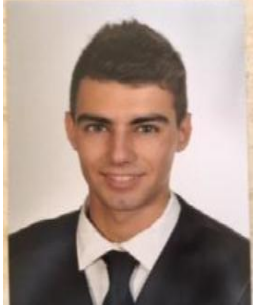

Joan Puigneró completed his bachelor's degree in Tourism and Hospitality Management at the School of Tourism, Hospitality and Gastronomy CETT-UB, University of Barcelona, Spain. He has worked in different hotels and is currently working as a front desk agent at a 4-star hotel located in the Spanish mountain region of Pyrenees. 